\title{
LOS EXTRANJEROS Y LOS MALES DE ESPAÑA Y AMÉRICA EN LOS TRATADISTAS HISPANOS (SIGLOS XVI-XIX)*
}

\section{MANUEL BUSTOS RODRÍGUEZ Universidad de Cádiz}

* El presente texto es, básicamente, el mismo que presenté como discurso de ingreso en la Real Academia Hispanoamericana de Cádiz el día 6 de junio de 1996.

Muy soberano señor: La mayor cosa después de la creación del mundo, sacando la encarnación y muerte del que lo crió, es el descubrimiento de Indias: y así, las llaman Nuevo Mundo (Historia General de las Indias, Zaragoza, 1552, Dedicatoria). Las palabras de López de Gómara dirigidas a su rey no parecen exageradas a la luz de lo que hoy sabemos, sino proféticas. Desde la expansión europea del siglo XV y, en particular, del descubrimiento de América, las cosas no podían ya ser igual ni para nuestro Continente ni para el mundo, menos para España, plenamente integrada en él (1).

La llegada de los españoles a América supuso, antes de nada, la ampliación de horizontes para los europeos. La tierra era ahora más grande y sus posibilidades de toda índole mayores. Pero también se cayeron muchos mitos y autoridades, antes apoyadas en construcciones mentales que en experiencias verificables. Caía, por ejemplo, el llamado Mar Tenebroso con sus leyendas de monstruos y sirenas encantadas y se hundía en el olvido la teoría acerca de la no redondez de la Tierra. Los seres fantásticos de las Antípodas, que con tanta frecuencia utilizara la iconografía de la época, se convertían en seres humanos similares a nosotros, aunque de costumbres, color y religión diferentes. Era preciso hacer un esfuerzo para conocer y asimilar todas estas cosas. $Y$ en ello tardó Europa no poco espacio de tiempo. A su vez se reabrieron otros mitos, tales los del Dorado, Cíbona o el Preste Juan (2).

La sociedad europea acusó el impacto de los descubrimientos. Al poco tiempo se organizó una corriente emigratoria hacia el Nuevo Mundo, cuyo término está lejos de haberse alcanzado aún. Tierra de promisión, en ella se pusieron no pocas esperanzas individuales y colectivas: de mejora social, de regeneración, de una vida nueva. Las fronteras entre nobleza y estado llano se hicieron mucho más permeables y se facilitó la creación de una "clase" anfibia, a caballo entre la burguesía y la nobleza. Las sociedades indígenas se vieron a su vez afectadas de forma irreversible. El indio, más tarde el negro, tuvieron que acostumbrarse a pensar a través de los esquemas del hombre europeo; sus tierras dejaron de pertenecerle plenamente.

La economía mundial dejó poco a poco de estar organizada en compartimentos isla para convertirse en una economía -mundo (3). Los 
contactos entre las metrópolis y sus colonias se fueron paulatinamente incrementando $\mathrm{y}$, a la larga, sus sistemas productivos se hicieron interdependientes. Los Estados se dieron cuenta del reto que suponía para sus países estos cambios e intervinieron, eso sí, de forma variable según los casos. Hacia Europa comenzaron a llegar los frutos exóticos de los nuevos espacios, así como los metales preciosos extraídos de las minas americanas. Con ellos fue posible atender el déficit de la balanza comercial europea con las Indias Orientales y enjugar en parte el que las monarquías habían contraído en la forja del Estado moderno.

La posibilidad de abastecer de productos europeos los extensos territorios americanos abrió nuevas perspectivas a los exportadores, comerciantes generalmente, bien conectados a los centros manufactureros de su Continente. Los colonos necesitaban telas para sus vestidos, aperos para labrar sus campos y explotar las fincas, elementos para el ajuar, mobiliario y obras de arte; también algunos productos alimenticios habituales en las mesas europeas. Aquellos países que mejor pudieran atender esta demanda, aunque fuesen más vulnerables a las fluctuaciones del consumo colonial, se colocaban en mejor situación para conseguir un aumento de su poder y riqueza, particularmente de sus burguesías comercial e industrial.

En España, protagonista cualificada del Descubrimiento, no tardaría en pasarse de la euforia que demuestra el texto de López de Gómara arriba comentado (visible también en el diario de Colón), a la prevención, cuando no al pesimismo (4). En efecto, una vez reconocida y a la vez proclamada la grandeza de la gesta, así como las enormes posibilidades de toda índole espirituales, políticas y económicas- que el Nuevo Mundo ofrecía, no había obstáculo en reconocer los problemas, muchos de ellos de nuevo cuño, que la posesión de las Indias comportaba. Fueron sobre todo los analistas de la sociedad y la economía de la época quienes mejor se percataron de ellos. Se trataba casi siempre de moralistas, incluso teólogos y religiosos, cuya bajada a la arena era obligada por su oficio. El caso de Bartolomé de las Casas, con todas sus exageraciones y las manipulaciones a que fue sometido, es un claro ejemplo de lo que decimos. Otro, más ajustado a la temática que en este artículo nos ocupa, Tomás de Mercado, se dirige a los comerciantes de las gradas de Sevilla por los años sesenta del siglo XVI para orientarles sobre los problemas de conciencia que el comercio de Indias está planteando, sea a causa de los crecidos préstamos que el mismo exigía, sea de las condiciones de compraventa de los productos (5).

Con independencia de los problemas morales que se reconocieron (lo que engrandece a estos hombres, máxime en los tiempos que corren, por comprender la dimensión ética de toda actividad humana) (6), a nosotros nos interesa aquí el poner de manifiesto la relación que tales observadores establecieron entre los males de su patria (especialmente de su economía) y la forma de relacionarse España con sus Indias; dentro de ello, la responsabilidad que cupo a los 
extranjeros. Nos interesan sus puntos de vista, sus argumentos y la evolución del tema.

En principio, por su protagonismo en el evento, pero también por el sistema monopolístico que la Corona estableció con respecto a América, el Nuevo Mundo podía haberse convertido para España en un colosal estímulo para su economía: Sin embargo, sabemos que no todos los países y personas pueden o saben reaccionar ante el mismo; de hecho, España y sus grupos productivos no respondieron al reto como habría sido de desear.

Hoy sabemos que, a finales del siglo XV comienzos del XVI, existía en la Corona de Castilla -a cuyos habitantes habían querido vincular los Reyes Católicos el aprovechamiento de las Indias recién descubiertas- una industria notable, fundamentalmente textil, es decir, la principal protagonista de la demanda de la época, una vez satisfechas las necesidades alimenticias. Las manufacturas se repartían por varios puntos del territorio castellano, si bien destacaban algunos centros por el volumen de su producción y la cantidad de sus telares. Este es el caso de las ciudades de Segovia, Córdoba, Cuenca y Toledo, esta última heredera de una larga y cualificada tradición sedera, a la que no habían sido ajenos 'los musulmanes allí afincados (7). Completaban la arquitectura económica castellana la feria de Medina del Campo, centro clave de contratación, a la par que mercado de dinero; Burgos, con su activo consulado de mercaderes, y los puertos de Bilbao, Laredo y Santander al Norte, junto con Sevilla al Sur, todos ellos indispensables para el funcionamiento del comercio y la industria de Castilla (8).

Sin embargo, a pesar de su importancia, tanto más llamativa cuanto que la Castilla contemporánea ha pasado a ser sinónimo de desindustrialización, las manufacturas del Reino no eran capaces de cubrir la creciente demanda de la región y, menos aún, la de su naciente Imperio. En esto existía un nítido contraste con las de los Países Bajos y el centro-norte de Italia, donde, desde la Edad Media, había una industria capaz de abastecer sus propios mercados y los ajenos (9). Las razones de esta incapacidad son diversas. La presión fiscal se fue acrecentando con el paso del tiempo, cebándose sobre medio rural, donde a la sazón se concentraba la mayor parte de la población activa, e impidiendo una demanda sostenida e, incluso, aumentada, en telas y paños sencillos, géneros habituales de los que surtían las fábricas castellanas. En cuanto a los grupos urbanos, cuya importancia fue creciendo paulatinamente, su consumo no se tradujo en un mayor acicate para la producción pañera castellana, antes bien prefirieron abastecerse de productos procedentes de otros países. Ni que decir tiene que América, mucho más lejos, sería pronto ganada por las manufacturas de Europa septentrional, capaces de surtir estos mercados a más bajo costo. Los exportadores castellanos se concentraron entonces en la saca de lanas hacia las industrias del Norte o en la de productos manufacturados que éstas producían hacia el Nuevo Mundo, sin olvidar el abastecimiento del mercado nacional con estos últimos. El déficit era saldado con el oro y, sobre todo, la plata proveniente de las minas americanas (10). 
La paradoja de un país poseedor de grandes riquezas, pero cuya dependencia económica del extranjero, incluídos sus propios enemigos, era un hecho, llamó tempranamente la atención de algunos observadores sensibles a los aspectos macroeconómicos. A punto de concluir el reinado de Carlos I, cuando las conquistas de los españoles en América tomaban carácter épico, un hombre de Hacienda, el contador Luis de Ortiz se quejaba ya de cómo los extranjeros se llevaban la materia prima fundamental de Castilla, la lana, cuya calidad estaba fuera de duda, para devolverla manufacturada y vendérnosla a mayor precio (11). A finales de la centuria, Pedro de Abreu, conocido de los gaditanos por su relato, fundamental, sobre el asalto anglo holandés a la ciudad en 1596, hacía una denuncia muy similar: España, estando bien dotada de todo cuanto da y ofrece la naturaleza para el sustento y regalo de los hombres, se ve saqueada por los reinos y provincias extrañas (sic), sacándo (le) la moneda con sutiles artificios e invenciones, que con ella se quiere hacer guerra en recompensa de tanto beneficio y España está falta y necesitada de ella. Los culpables son esos comerciantes situados en los puertos españoles, que extraen en trueco de impertinentes mercancías, grandes intereses y riquezas y la mejor sustancia de sus frutos (así como) toda la moneda labrada de oro y plata que podía haber. A falta de oportunidad de trabajo, los naturales se han dado al ocio; sus cuerpos, carentes de ejercicio, se han debilitado y los ánimos necesarios para la lucha se han vuelto cobardes y tímidos (sic). Perdidos los deseos de ganar con su propio esfuerzo, los españoles sólo se preocupan de conseguir el dinero que necesitan para comprar las mercancías extranjeras de su uso, sin preocuparse de aprovechar los recursos que su feraz naturaleza les proporciona (12).

Pero lejos de asumirse las propias responsabilidades, los tratadistas preferían por lo general trasladarlas al elemento extranjero y, más concretamente, al afincado en España, haciéndole culpable de los graves males que afectaban al país y sus habitantes, puesto que la economía, hoy como ayer, afectaba todos los ámbitos, desde el social al político, pasando por el de las propias costumbres o el religioso. Entrados ya en el siglo XVII, un "arbitrista" bien conocido, Sancho de Moncada (13), expresaba sin ambages que los extranjeros tienen deshauciada a España (14). Para este autor, ellos eran los responsables de dos problemas fundamentales: la evasión de divisas y el paro, intimamente unidos ambos al empobrecimiento general del país. Veamos cuales son sus argumentos.

La necesidad de comprar a los extranjeros manufacturas para cubrir las necesidades, tanto de la demanda interna como de la indiana, obliga a pagarles en metales preciosos, que Moncada llama cosecha de España; con lo que las reservas monetarias disminuyen y otros países se benefician de la plata y el oro que pertenecen a los españoles. En su opinión, sólo en mercaderías, los extranjeros se llevan 20 ó 30 millones, en pasta o barra, quitándole al propio Estado hasta las posibilidades de acuñar. Acaparan asimismo cinco sextas partes de lo negociado en España e Indias. Por si fuera poco, al no cumplirse la 
ley que les obliga a comprar con el dinero que ganan mercancías nacionales, los españoles no se benefician y se evaden divisas. Con ello, el Reino empobrece y la Hacienda pierde ingresos (15). Habría que preguntarse qué productos atrayentes podía ofrecer a los extranjeros España.

Pero, además, las divisas extraídas por los extranjeros dejan de circular en el país, razón por la cual disminuye la demanda (la gente tiene menos dinero para gastar). Al descender ésta disminuye la producción y con ello los puestos de trabajo. Ante las menores perspectivas de colocación se reduce la población (es de entender, aunque no lo dice, que por caída de las tasas de natalidad y emigración hacia aquellos países en donde halla posibilidades de trabajo)(16). Más aún, los extranjeros trabajan en todo tipo de oficios y han excluído de ellos a los naturales (no sabemos si por incapacidad de estos, mayores prejuicios por razones de honra o, sencillamente, por menor competencia) (17). Por otro lado, se llevan las materias primas que les son útiles (piénsese en las lanas) y quitan el trabajo que pudiera hacerse en la Península para su transformación, pues no faltan, en su opinión, habilidades para realizarlo o, si faltaran, se podría ir aprendiendo (18). De la manera que sea, lo que preocupa verdaderamente a Moncada no son tanto las carencias nacionales, cuanto las facilidades otorgadas a los extranjeros entre nosotros (así, en la captación de rentas, en la venta de géneros en puertos francos o en la exención de impuestos para ciertos géneros), en contra de las disposiciones legislativas de carácter limitatorio (19).

La Hacienda pública se ve también afectada por este efecto dominó. Al enfriarse la economía nacional por los motivos aludidos, disminuyen igualmente las transacciones mercantiles y, con ello, los impuestos que, como las alcabalas gravan las mismas y representan una de las fuentes principales de ingresos de la Corona desde la Edad Media (20).

Las conclusiones que Sancho de Moncada extrae de sus análisis no pueden ser más radicales. Las Indias -nos dice-trajeron a España la raíz de todos sus daños (21). Pero, no nos engañemos, las desgracias no vinieron de ellas en sí mismas, sino de las ingerencias protagonizadas por los extranjeros. Estos, explica nuestro analista, nos tratan como a Indios, sacando grandes sumas de fruslerías y juguetes, que son de gran perjuicio por superfluas, y contra toda ley de buen gobierno (22). Imponen, incluso, las modas que les convienen, obligando a los jóvenes en edad de casarse a postergar el matrimonio por no tener dinero para costearse un traje de boda acorde con ellas; esto, según Sancho de Moncada, contribuye también a la despoblación peninsular (23). A la vista de tales abusos, no debe resultarnos extraño que se proponga con los ocho discursos que componen su obra el siguiente objetivo: que cese el comercio de extranjeros (que ha sido la única y sola raíz de todos los daños de este reino...) (24).

Otro escritor "arbitrista", Francisco Martínez de Mata, redacta entre 1650 y 1660 varios discursos y memoriales que dirige al rey Felipe IV (25). Está preocupado por los males que asolan a España y su Imperio, intensificados en estos años por la derrota en los campos de Europa (Münster y Osnabruck en 
1648; los Pirineos en 1659) y la recesión económica y demográfica (26). Como su antecesor, Martínez de Mata sitúa al elemento foráneo como responsable, si no único si fundamental, de lo que está ocurriendo. Los extranjeros -dice metafóricamente- son lo que el fuego en la vela, que si baja contra su centro, es mientras halla el pábilo proporcionado que convierte en ceniza, y si aplica alguna parte de su calor abajo, es sólo lo que basta para poder ir tomando del combustible lo que envía a su esfera (27). Analicemos ahora sus argumentos.

Martínez de Mata, al igual que su antecesor, considera que la causa única (sic) de la despoblación, el empobrecimiento y la esterilidad de España, así como del empeño del Estado, está en los extranjeros y no en los impuestos, cuyo peso se hacía más oneroso, en la misma medida que la riqueza de los contribuyentes disminuía, como sostenían otros observadores (28). Al contrario, países de por sí pobres, se habían hecho ricos a costa de España. La causa de todo ello está en el amplio consumo que se hace en ella de productos extranjeros, comprados por los nacionales a precios más elevados de los que saldrían de haber sido elaborados en el país (29). Este hecho desencadena el consabido círculo vicioso: las importaciones de manufacturas extranjeras impiden o menguan el desarrollo de las propias, quitan puestos de trabajo y empobrecen a los súbditos. De ahí se deriva la caída de las rentas de estos, la pérdida de su capacidad contributiva y, por ende, la disminución de los ingresos por parte de la Hacienda pública (30). Los tributos, necesarios, en vez de recaer sobre las utilidades del vasallo, como sería natural, lo hacen sobre lo que tiene para vivir él y su familia, pues sus beneficios o ganancias son prácticamente nulos. La despoblación consiguiente obliga a que el deber de contribuir recaiga cada vez más sobre un menor número de sujetos y a que estos tengan que soportar sobre sus espaldas más altos gravámenes (31). A mayor abundamiento, la disminución de operaciones de compra-venta y, con ello, de la alcabala por la caída del consumo, repercute también negativamente en el Tesoro público, que deja de ingresar una parte importante de lo que le corresponde por impuestos indirectos (es decir, los que recaen sobre la compra de ciertos productos básicos). La Hacienda, exhausta, ha de recurrir a los préstamos de particulares; en definitiva, al empeño, en tanto que esos, animados por la emisión de deuda pública (los llamados juros), canalizan su ahorro hacia la compra de la misma, así como hacia la percepción de otras rentas similares, mucho más seguras que las del comercio (32).

Nuestro autor describe con más precisión que Sancho de Moncada el ciclo generador de riqueza. El consumo, incluso el superfluo, es necesario para que aquélla se pueda formar, pues al adquirir un producto, el comprador contribuye a mantener los puestos de trabajo de quienes lo fabrican, y estos, a su vez, con su consumo propio, ayudan a conservarlos e, incluso, ampliarlos en beneficio de los demás (33). Sin embargo, en el caso español, al tratarse de un consumo de manufacturas no fabricadas en el país, lejos de animar el ciclo arriba descrito en provecho propio, lo hacen en favor de las naciones extranjeras, que son quienes verdaderamente recogen los frutos. Además, las adquieren a más alto precio, pues junto con el coste de su fabricación y transporte, pagan la parte que 
corresponde al Estado de donde provenga la mercancía en concepto de impuesto. Si las mercaderías que consumen los vasallos son extranjeras expresa Mata-, es preciso que lleven (sobre sí) la carga de los tributos que de ellas sacaron los Reyes extraños (34).

El problema producido por la introducción en España y sus Indias de mercancías extranjeras no es sólo cuantitativo (pérdida de puestos de trabajo), sino también cualitativo (pérdida de determinados oficios y habilidades). Mata hace de genoveses y franceses los principales responsables de haber arrebatado a España su industria. El comercio de Indias, que en un principio fue beneficioso para los nacionales, pudiendo así éstos mantener sus manufacturas y el Erario sus rentas, se tornó perjudicial desde que, en 1518, se introdujeron en él los genoveses. Los galeones regresarán de América con las bodegas llenas de mercancías españolas sin vender (Mata se refiere concretamente a ropa) y aquí, en la Península, tampoco podrán hacerlo debido a la competencia de las manufacturas genovesas. Se reducirán por tanto los pedidos a las fábricas españolas y el comerciante nacional habrá que subordinarse al extranjero (35).

Tampoco los franceses le van a la zaga: La llegada de éstos, en número que Martínez de Mata sitúa en 120.000 , ha quitado el trabajo a muchos españoles, al monopolizar ciertos oficios (que los españoles tenderán a olvidar) y dejar luego la plaza a sus paisanos; al tiempo, regresan a su país sin apenas haber hecho gasto alguno en el nuestro (ahorran al máximo para llevárselo luego a su tierra) ni pagado impuestos. Ello sin contar las mujeres que dejan abandonadas y los problemas de herejía, pues no pocos de ellos son hugonotes (36). Extrañamente, nuestro autor les acusa de hacer la competencia a los españoles al dar un mejor servicio, con lo cual roban las voluntades; así como de adaptarse mejor a las circunstancias para obtener lo que desean. La conclusión del análisis de Martínez de Mata es obvia: Conservar los extranjeros (...) es evidente riesgo (37).

Setenta años después (1724), Gerónimo de Uztáriz recoge esta tradición que entiende como nefasta la intervención de los extranjeros en la economía española (38). Está todavía reciente la firma del tratado de Utrecht que concede a los ingleses una presencia importante en el monopolio español con sus Indias. En este contexto, nuestro autor considera que los extranjeros, a la fatalidad de despojarnos desde Cádiz, o su Bahía de la mayor parte de los millones que traen nuestras Flotas, y Galeones, (añaden) el gran desconsuelo de que se lo lleven diversas Naciones desafectas de la Monarchía, para facilitar sus comercios, y opulencia (39).

Los años por los que escribe Uztáriz su Theórica y práctica de Comercio $y$ de Marina, coinciden con el recrudecimiento de la beligerancia entre el Consulado, como representante oficial de los comerciantes españoles de la Carrera de Indias, y sus homónimos extranjeros, a la sazón excluídos de él (40). 
La insistencia en el tema, a pesar de los numerosos años transcurridos, obligan a pensar que se trata de una problema estructural que ni la Corona ni los españoles habían logrado solventar. Pero ello no quiere decir que no se hubiesen ofrecido al rey soluciones, pues éstas, en realidad, abundaron.

Luis de Ortiz abogaba a mediados del Quinientos por impedir la exportación de las lanas castellanas, conservándolas para que fuesen manufacturadas en el propio país. Eran, como hemos dicho, los años mejores de las pañerías y telares de Castilla.

A fin de atajar la salida de numerario que tanto le contrariaba, el arbitrista Moncada, para quien riqueza y moneda eran equivalentes, propone varias medidas: una, que en lugar de ser los españoles quienes deban a los extranjeros por haber consumido sus mercaderías, sean éstos deudores de los nacionales (lo que presupone una venta de nuestros productos por encima de la compra de los extranjeros); segundo: en lugar de proponer una mayor competitividad de nuestros productos, que se prohíba sacar materiales (es decir, materias primas, a excepción de aquellas que no nos son útiles ni puede dañarnos su posesión por los enemigos), y entrar mercaderías labradas; siguiendo con las medidas monetaristas: evitar que se acuñe moneda falsa, haciendo corresponder el valor nominal y el valor intrínseco de la moneda de vellón o de cobre (41).

Aparte de tales prevenciones, el Estado debería gravar (desde el punto de vista impositivo se entiende) a los extranjeros que entran en el pais, a fin de disminuir la inmigración de estos hacia España y de provocar una respuesta igualmente restrictiva por parte de los reinos extranjeros que desanime la emigración de los nuestros hacia los de ellos (42). Otro tanto propone Sancho de Moncada se realice con las mercancías extranjeras, aumentando el peso de las alcabalas sobre ellas, cobrándolas en los puertos para evitar la penetración de las mismas hacia el interior, e impidiendo que se beneficien de las exenciones de que gozan algunas provincias del Reino, pues de esta forma se aumenta su precio y se las hace, en definitiva, menos competitivas que las españolas (43). Además, los extranjeros deben pagar los derechos que les correspondan en género (sic) y no en moneda, a similitud del diezmo, para que puedan ser vendidos después por manos de españoles y consigan estos quedarse con los beneficios y evitar la competencia (44). Por último, a fin de evitar, o siquiera paliar, la dependencia de la Hacienda con respecto a los prestamistas extranjeros, que la Corona posea sus propios fondos, su propio tesoro; en otras palabras, que tenga solvencia económica suficiente para hacer frente a sus deudas (45).

En última instancia, todo va dirigido al objetivo final de impedir que entre en el Reino cosa que impida el trabajar -tal sería la consigna- y erradicar el ocio obligado (46). El daño que se hace a los mercaderes al prohibir la entrada de las mercancías extranjeras en España se compensa, según Sancho de Moncada, con la esperanza de llenar el vacío que éstas dejan. La probable reacción restrictiva a la importación de mercancías españolas por parte de los países competidores 
será agua de borrajas ante la necesidad que éstos tienen de las materias primas que proveen los españoles y, en especial, de los metales preciosos que traen (47); por si esto fuera poco, España tiene mercados más que sobrados en sus propias Indias y los comerciantes foráneos, sobre todo los socios del Imperio, se han de ver obligados a unirse a los hispanos para poder continuar su comercio; de ahí surgirán todo tipo de compañías mixtas (48). El aumento de las fábricas nacionales ha de atraer expertos del resto de Europa. La posibilidad de guerras con fondo comercial queda conjurada por la propia fortaleza de España, que hace de ella un contrincante temido y feroz (49).

La lucha contra los "metedores" de mercancías extranjeras debe hacerse mediante un tribunal de jueces seglares (sic), que actúe imitando a la Inquisición, es decir, procediendo contra ellos, afrentándolos y condenándolos a muerte cuando fuesen culpables. Para su mantenimiento se le dejará en usufructo lo que se cobrare por derechos de los extranjeros, así como el producto de las denuncias (50).

En el caso de Martínez de Mata, las críticas parecen dominar sobre las propuestas. No obstante, en un largo párrafo de carácter metafórico, que no nos resistimos a reproducir, alterna ambas en dosis diferentes.

El remedio consiste en limpiar primero la fuente y en aclarar los venenos de donde proceden sus copiosas aguas, tratándose de quitar las sanguijuelas extranjeras (obsérvese la expresión), que como esponjas chupan con sus sutiles modos, y politica que observan a este fin, el oro y plata que es la sangre manantial del cuerpo de esta Monarquía; y no dan'lugar a que pase su virtud a la cabeza, ni a los demás miembros, y dejen a los vasallos que coman como pudieren, porque no perezcan en el interin que se les restituye el comercio usurpado con que vivian antes (51)

¿Pero cómo conseguirlo? Mata pide que se restauren las artes, o lo que es lo mismo, la industria: que no se gasten en estos reinos ni en las Indias cosa fabricada fuera de ellas. Los gremios de artesanos deben demandar que se cumplan las leyes restrictivas para los extranjeros y sus productos. En Mata la legislación española parece ser suficiente para solucionar las graves carencias de la manufactura española y que la riqueza fluya en nuestra economía reconstruyendo el ciclo; lo fundamental es, así pues, que se cumpla. Para pedirlo nuestro personaje propone que todas las Artes, tratos, oficios y modos de vivir del Reino, unánimemente, nombren un representante que, en nombre de todos, exija ante el Consejo ( $i$ de Castilla?) el cumplimiento de las leyes que les favorecen (52). Entre ellas, conviene poner en marcha la que, en 1622, creaba los erarios o montes de piedad, aún incumplida. El fin de los erarios es, en opinión de Mata, el de conservar con su caudal el de todos. Otro problema sería, y no menor, de dónde obtener los capitales necesarios para su funcionamiento (53).

Recordando las leyes restrictivas, Martínez de Mata pide al monarca que se exija a las mercancías extranjeras el pago del cien por cien, todas las veces que 
se vendieren o revendieren, en tanto las españolas sólo pagarían lo estipulado en España e Indias por concepto de alcabalas y derechos usuales. La separación de mercancías según origen se hará en América por veedores (sic) de confianza del gremio de importadores de manufacturas españolas que allí debe crearse. Para estimular a los comerciantes y fabricantes de las mismas, el rey tendría que otorgarles ciertos privilegios y exenciones que Mata no especifica. Por último, propone dignificar el oficio de comerciante y artesano, no tomándolo como desdoro de la condición de noble (54).

Coincidiendo con la llegada de los Borbones al trono de España, las cosas empezaron a cambiar en ella. En el ámbito internacional, la nueva monarquía podía verse liberada de una parte considerable de sus cargas en Europa. La paz de Utrecht, firmada en 1713, supuso para nuestro país la pérdida de sus territorios de los Países Bajos y, temporalmente, también de los italianos. Podía, pues, concluída la Guerra de Sucesión, y aprovechando el período de paz que se abría, poner orden en sus asuntos internos y, sobre todo, organizar mejor su economía, con vistas a aprovechar sus recursos y hacerse menos dependiente de las industrias y comercio extranjeros. Sin embargo, a pesar de los esfuerzos realizados desde el poder (mejora de la marina mercante, reformas parciales en el sistema hacendístico, creación de manufacturas de iniciativa estatal, etc.), los resultados no fueron satisfactorios (55). Así pues, no parece posible que el panorama pudiera cambiar mucho con respecto al que se había heredado de la anterior centuria. Es sintomático que no pocas de las acusaciones esgrimidas por los "arbitristas" en el XVII siguieran aún en vigor y que, a pesar de la acusación de desorientados que Jovellanos les hiciera en 1788 (56), sus textos fueran reeditados precisamente en esta época y sirvieran de inspiración a no pocos de los textos de Campomanes, a la sazón verdadera eminencia gris del reinado de Carlos III. Si es verdad, en cambio, que los planteamientos mercantilistas y bullonistas que aquellos básicamente esgrimieran, fueron lentamente abandonados en favor de los nuevos aires económicos liberales que corrían por Europa. Desde éstos, precisamente, van a venir las críticas y las alternativas más importantes.

Por los años veinte se iba a lanzar una importante ofensiva desde el Consulado establecido en Cádiz, apoyado por el Consejo de Indias, contra los comerciantes extranjeros (o mejor, contra sus hijos), mucho menos teórica y, por tanto, más concreta que la de los tratadistas del XVI-XVII; en todo caso, sostenida durante más de dos décadas, hasta que las ideas de liberar el comercio de Indias vayan tomando cuerpo entre nuestros gobernantes (57). La polémica sobre los jenízaros -como se denominaban entonces a los hijos de los comerciantes extranjeros- estuvo presente casi desde los primeros tiempos de la expansión española en América (58). La legislación de la época les era en general adversa. Ahora, sin embargo, alcanza uno de sus momentos álgidos, cuestionándose hasta la legalidad de los mismos para ejercer el comercio con el Nuevo Mundo. La queja tenía como telón de fondo la competencia que los jenízaros ejercían sobre los comerciantes españoles, al suplantarlos en la 
Carrera de Indias en su tradicional papel de intermediarios. A nosotros nos interesan sobre todo los argumentos esgrimidos.

En el año 1722, los comerciantes oriundos se reunían para nombrar quien les representara en el contencioso que mantenían con la Casa de Contratación, el otro gran organismo de la Carrera de Indias, que a la sazón se había puesto del lado de los jenízaros. Allí se propone como objetivo el lograr la deseada y precisa restauración del comercio español, acosada, reprimida y extinta, con la libertad y tráfico de los extranjeros y sus hijos, fuera de las reales leyes que lo prohíben (59). El propósito que manifiestan, a pesar del tiempo transcurrido, no parece muy alejado del de los tratadistas que hemos venido analizando en la primera parte de nuestro discurso: se habla aquí de un comercio nacional inexistente (que es preciso "restaurar", palabra que ya utilizara el "arbitrista Caxa de Leruela, para título de su obra en 1631) (60), de los culpables de esta situación (los extranjeros y sus hijos) y, finalmente, del incumplimiento de las leyes promulgadas para impedirlo (queja ésta que ya escucháramos también a Mata). En definitiva, un panorama muy similar al de los escritores analizados.

En su réplica, la Casa de Contratación recordaba la inconsistencia de la queja de los oriúndos españoles: los comerciantes hispanos se habían hecho ricos gracias a los caudales (al crédito) de los extranjeros y, por tanto, la consideraba ingratitud indigna y codicia desordenada (sic) (61). Por su parte, el propio Gobierno reconocía la debilidad de la economía nacional $y$, consiguientemente, la necesidad de seguir utilizando los indispensables servicios de los extranjeros, cuando, en Real Cédula de 12 de febrero de 1722, concedía a los comerciantes españoles autorización para cargar mercancías extranjeras con rumbo a las Indias por la falta de caudales y fábricas existentes en el Reino. Era, sin duda, el reconocimiento de una impotencia, de una frustración, puesto que no se era capaz de arbitrar una solución adecuada, y, sin embargo, el discurso realizado desde las instituciones sobre los extranjeros seguía siendo acusatorio contra ellos. El Consejo de Indias, por ejemplo, expresaba la necesidad de luchar contra la rapacidad (sic) de aquellos sobre las riquezas de España, en tanto que su fiscal acusaba a los antepasados de los jenízaros de haber arruinado al país y, al mismo tiempo, de haber practicado comercialmente conexiones de parentesco y amistad con motivo del comercio de las encomiendas (62).

Patiño, en esta época Presidente de la Casa de Contratación, era mucho más realista. Pensaba que la Pragmática de 1722 aventaba las vergüenzas hispana, o, lo que es igual, la ninguna sustancia de sus comercios, pues en ella se reconocía públicamente la imposibilidad de cumplir las leyes que prohíben a los extranjeros participar en el comercio de Indias. Así pues, la ficción debía continuar y, por tanto, la ley, pero abogaba en favor de cierta tolerancia hacia aquel que sirviera de intermediario, fuera éste español o jenízaro (63).

La propuesta de Patiño no fue escuchada. Una nueva pragmática de 1722 (18 de diciembre) volvía a rechazar a los extranjeros, si bien reconocía al mismo 
tiempo la necesidad de seguir dependiendo de ellos, aunque buscara no airear la situación, por otra parte de todos conocida (64). Entretanto, el Consulado no cejaría en los años siguientes en su ofensiva por eliminar la presencia foránea de la Carrera, hasta que lo consiguió en 1729, mediante la creación de un cuerpo de comercio legal (65). A él sólo podían tener acceso los que el propio Consulado quisiera; es decir, todos los comerciantes mayoristas de Indias, a excepción de los extranjeros y sus hijos (e, incluso, nietos). Entre 1729 y 1741 no sería admitido ningún jenízaro en la matrícula consular y los permisos para viajar al Nuevo Mundo fueron muy estrictos. Incluso se otorgaron "donativos" a la Corona, a fin de que ésta no tomase los de los jenízaros.

Sin embargo, como ya hemos advertido anteriormente, los aires liberales iban abriéndose paso poco a poco, y ya por los años cuarenta del siglo empezaban a triunfar en las altas esferas del Estado. Por este tiempo se fue extendiendo el sistema de navíos sueltos en detrimento del más tradicional de flotas y, con anterioridad, se habían hecho importantes concesiones a ingleses (Utrecht) y franceses (Pactos de familia de 1733 y 1743) en el monopolio indiano. El Proyecto económico de Bernardo Ward (1762), por muy calcado que esté en algunas de sus partes de otro anterior de Campillo, demuestra bien a las claras la evolución que se estaba experimentando en los ámbitos del Poder (66).

Ward poseía, por su largo periplo por Europa entre 1750 y 1754 (había llegado hasta Lituania, Noruega y Moscovia, pasando por Inglaterra, Francia y Flandes) y su participación como miembro en la Junta de Comercio, una importante experiencia (67). En su obra, realiza un diagnóstico muy similar al de sus antecesores. El sistema utilizado en la Carrera de Indias hasta entonces no es válido. ¿Motivo? Ha reducido a casi nada -nos dice- un comercio como el de América y ha transferido a los enemigos de España los tesoros de Méjico y del Perú. De esta forma, se ha imposibilitado la extracción de los frutos nacionales, dándose preferencia al contrabando sobre el comercio legítimo. El éxito será un hecho -matiz importante- cuando los frutos y géneros enviados a las Indias sean españoles, no sólo los comerciantes que los envían (68).

Pero, para conseguir un cambio de situación, Bernardo Ward propone ya otras soluciones distintas a las de los teóricos de los siglos XVI y XVII. Su punto de mira no está en los extranjeros y en la responsabilidad de estos como causantes del problema de dependencia de España y sus colonias con respecto al exterior, sino en los propios nacionales y, más concretamente, en la política económica seguida hasta entonces. Por ello propone -en primer lugar- que se liberalice el comercio de los españoles con sus Indias, permitiendo a los súbditos no castellanos de la Corona, en igualdad con el resto, que puedan llevar allá libremente sus efectos, aunque tengan que seguir haciéndolo por Cádiz. Esto supondrá, en opinión de Ward, un ahorro considerable en gastos de defensa para el Estado, pues todos deberán ahora colaborar de igual menera a ella, ya que tienen intereses allí (69). 
Nuestro personaje baraja aún otra posibilidad: permitir que se establezcan en América fábricas de todos los géneros, lo que rompería con la tradicional posición mercantilista, para quien las colonias no son sino meras suministradoras de materias primas a las manufacturas de la metrópoli o simples exportadoras hacia el extranjero por mediación de ésta. Así, las fuerzas productivas de la Península no se desarrollaban, pero, al menos, aumentaría la riqueza en el Nuevo Mundo y con ello también la del Erario público, además de debilitarse el comercio y las ganancias de los enemigos. Esta medida es -en opinión de Ward-menos importante que la de abrir el comercio, pero mejor que dejar las cosas como están (70).

El cambio supone la ruptura del teórico monopolio exclusivo de la metrópoli , mantenido desde los orígenes de la conquista, y, por lo tanto, su puesta en marcha podría realizarse por pasos. En primer lugar, se liberalizarían los frutos (o, lo que es lo mismo, las materias primas); a continuación, uno o dos géneros nacionales. No obstante, según nuestro autor, conviene mejor liberalizar de una vez todos los productos españoles, sean éstos frutos o géneros, cargándoles para Indias los mismos derechos que para Europa (71).

La nueva actitud se palpa también en el tema de los extranjeros, a quienes los antecesores de Ward habían hecho el chivo expiatorio de casi todos los males de la economía española. Nuestro autor se preocupa de ellos, sin duda considerando que su presencia entre nosotros es necesaria: Las medidas propuestas por él, lejos de perjudicarles, les sirven de provecho, puesto que serán ellos los encargados de cubrir la parte del consumo americano, ahora aumentado, que no sean capaces de cubrir los españoles (72).

Los desgravámenes apuntados han de comenzar en una provincia concreta de las Indias, para luego extenderlos a otras, a fin de no perjudicar a la Hacienda si se le priva de muchos ingresos de golpe. A tal efecto, la Aduana de Cádiz deberá calcular el volumen de lo pagado en ella. Igualmente se debe intensificar el comercio con Asia desde Nueva España (73).

Además de la liberalización del comercio y el control del contrabando, Ward propone que la oferta de nuestros productos se adapte a la demanda de los indios, por lo general de pocos medios. Con ello se podrá competir con las fábricas americanas, y a medida que vayan aquellos saliendo de la pobreza, podrán dirigir su consumo hacia manufacturas de más lujo, al mismo tiempo que permitirán a las de la metrópoli adaptarse a la nueva demanda y aumentar de esta forma el número de empleos. Pero para ganarse al indio a fin de venderle nuestros productos, hay que procurar que nuestra comunicación sea útil y gustosa (...), sin pretender derecho alguno sobre sus bienes, ni sobre su libertad (74).

Bernardo Ward propone que se industrie al indio; es decir, que se le asocie al trabajo para la obtención de materias primas. De esta forma, nuestros frutos podrán competir con los extranjeros, al salir a más bajo precio que los de, por 
ejemplo, franceses e ingleses, quienes han de comprar mano de obra esclava que los encarece (75).

Se debe de fomentar el comercio entre Nueva España y Asia a través de las Filipinas, bien sea intercambiando con los países asiáticos, bien con los europeos allí instalados. Manila serviría para obtener la plata necesaria a los pagos; Acapulco recibiría las mercancías (eso sí, de calidad), gravadas con derechos muy elevados (76).

En punto a la evasión de las divisas por el déficit comercial, que tanto había preocupado a los arbitristas, Ward se muestra más condescendiente . No debemos pretender -dice- que no disfruten otras naciones aquella parte (de la plata) del comercio de nuestras Indias que nosotros no podemos abastecer, aunque más convenga dárselo a los chinos, que están más lejos, que a los europeos, quienes, al estar cerca, podrían usarla en desfavor nuestro (77).

En resumidas cuentas, los extranjeros comienzan a ser menos culpables de lo que se les suponía en la mala situación económica de España y en la postración de ésta. Es preciso fomentar el comercio y, para ello, nada mejor que introducir en él y la industria una cierta liberalización. En esta línea se sitúa también Campomanes, inicialmente protegido de Ward, con quien la llustración y el reformismo borbónico alcanza su apogeo. El asturiano realiza varios comentarios a los Discursos de Martínez de Mata (1777), donde nos expone sus diferencias con el arbitrista, al tiempo de darnos su punto de vista sobre el tema (78).

Campomanes piensa, como los ilustrados de la época carolina (vid. el caso de Jovellanos) en general, que sus antecesores se han centrado excesivamente en la exposición de quejas y que las soluciones por ellos propuestas no eran sino, eso, meros arbitrios que no acertaban sobre las causas verdaderas de los males. En otras palabras: que tomaban el rábano por las hojas. No vamos a extendernos aquí sobre las importantes propuestas de Campomanes y de otros ilustrados contemporáneos acerca de las medidas que será preciso adoptar para mejorar la penosa situación económica, pues ello exigiría la extensión de, al menos, un nuevo artículo (79). Por otro lado, no es ésta la tarea que nos ha traído aquí. Veamos, pues, cómo ha visto Campomanes el problema de los extranjeros en relación con la economía.

La culpa de la dependencia económica de España y de sus nefastas consecuencias para el país no la tienen los extranjeros como habían pensado los arbitristas, sino los propios españoles. Para el asturiano el problema que denuncia Mata es debido a que sus compatriotas pusieron en aquel tiempo unas trabas universales al comercio de Indias. Prefirieron lo que él denomina abusos clandestinos a una legislación generosa y difusiva a toda la nación y a cuantos quisiesen venir a incorporarse en ella como ciudadanos. Y añade: Aprendamos de otras naciones a dispensar favor a los extranjeros católicos que tengan industria, arte o caudal que aumente la circulación y la opulencia nacional 
(80). Todo lo contrario, pues, a la actitud, hostil y proteccionista, defendida por los tratadistas de los siglos XVI-XVII. ¿Se trataba de un convencimiento o del mero pragmatismo de quien se sabe impotente para combatir a los extranjeros, y prefiere sacar de ellos el máximo partido posible? De la manera que sea, se ha abierto definitivamente una nueva era. ¿Qué debieron de hacer los españoles de los tiempos de Mata en consecuencia? Campomanes propone cuatro acciones (81).

La primera: puesto que existía la denunciada dependencia de España con respecto al extranjero en lo que a manufacturas se refiere, comprar los nacionales los productos extranjeros, sin intermediarios, a pie de fábrica (sic). Segunda: asociarse los comerciantes españoles con los residentes en las principales plazas de América para tener caudales y naves propias con que hacer las compras de primera mano y transportar en aquellos buques las mercaderías. Tercero: la liberalización del comercio de Indias; es decir, abrirlo a todos los puertos de la Península e islas adyacentes (la medida no se adoptaría legalmente hasta el año 1778 , o, lo que es igual, uno después de la reedición de los Memoriales y Discursos de Mata). De esta forma, pensaba el asturiano, toda la nación se habría vuelto comerciante (deseo similar al que expresara en el XVII el conde-duque de Olivares), animando la extracción de los frutos y manufacturas de cada provincia. Cuarto: flexibilizar la naturalización de comerciantes extranjeros, por cuyo medio -según Campomanes- se habrían arraigado un buen número de casas ricas en nuestra Península, comprando haciendas y tal vez estableciendo fábricas.

Lejos, pues, de aislar al elemento extranjero, aprovecharse de las ventajas de su presencia. Por eso, el problema de los jenízaros se ve ya desde otra óptica. Campomanes comienza declarando que los hijos de extranjeros industriosos son tan españoles como el resto de la nación. Más aún, es cosa evidente que la admisión de extranjeros católicos e industriosos es conforme a nuestras leyes y uno de los medios de repoblar el reino, administrándoles exacta justicia como a los demás vasallos (82). El asturiano justifica la política carolina de nuevas poblaciones, que se iniciará bajo su inspiración poco después.

Junto a los beneficios económicos producidos hay que poner también los demográficos, que en la teoría campomanista no se ven como algo separado, sino concurrente. Así, remplazando el número de personas regnícolas que emigran a las Indias con la población de católicos extranjeros, unos y otros dominios sin causarse perjuicio, crecerían a la par y darian solidísima consistencia a la nación española y a la monarquía (83).

Los extranjeros no son los culpables de que los españoles hayan abandonado ciertas labores o, en general, el trabajo. Antes bien, es la vulgaridad (sic), la incultura, el desconocimiento, quienes lo han producido. Es a sus instigadores, precisamente, a quienes es preciso desterrar y no a los extranjeros. Y en la misma línea de aprovechamiento de la circunstancia, Campomanes abre las puertas a los españoles para que acudan a formarse en el extranjero en 
aquellos oficios, técnicas o conocimientos que redunden después en beneficio del país (84).

En resumidas cuentas, no se debe poner tanto el acento en el dinero que se va, porque éste para Campomanes es en sí estéril; o, lo que es igual, es (mera) representación de las cosas; (que) en sí mismo no induce riqueza alguna permanente. Antes bien, el acento hay que ponerlo en la generación propia de riqueza mediante el cultivo y desarrollo equilibrado de los tres grandes ramos de la economía (agricultura, industria y comercio), y eso corresponde a los mismos españoles y a sus autoridades favorecerlo. Una nación que tuviese todo el dinero que se ha acuñado en el universo -expresa Campomanes-, si careciera de agricultura, industria y artes tendría que soltar a cierto tiempo toda esta masa de dinero a los extranjeros que le trajesen los frutos y mercaderías de su consumo (85). Tal fue lo ocurrido en el pasado. Los tratadistas de este tiempo confundieron con excesiva frecuencia riqueza con dinero.

La posición liberalizadora y prágmatica hacia los extranjeros que iniciara Ward y confirmara Campomanes, es asumida, como no podía ser menos, por los liberales. No podemos adentrarnos aquí en su pensamiento al respecto, por quedar ya fuera del marco cronológico que nos habíamos impuesto. Pero si vamos a dejar indicada la tendencia a través de la posición, en cierta medida modelo, de uno de los liberales españoles más conspicuos: Alvaro Florez Estrada, que publica su Curso de economía política en Londres el año 1828, en plena década ominosa.

Para Estrada es un error muy común (sic) creer que la industria de los extranjeros que se establecen en un país o de los que van a él periódicamente a realizar una serie de faenas, perjudica notablemente a la industria de la nación y disminuye su riqueza (86). En su opinión, esto se debía a la confusión que introdujeron al creer que el dinero era la única verdadera riqueza, ignorando que es la industria el solo fundamento de la prosperidad de las neciones. De ella depende la abundancia y los medios de subsistencia, de la que depende el aumento de una población feliz (87). Al irse la moneda en pago del consumo de productos extranjeros realizado, se pensaba, pues, que España perdía su sustancia, y hasta algo de su propio ser. Los extranjeros eran como sanguijuelas -clara alusión a los arbitristas- que chupaban la verdadera riqueza del país.

Por el contrario, Estrada pensaba que la riqueza estaba en el trabajo humano, con independencia del sujeto, nacional o extranjero, que lo ejerciese. Más aún, cuanto mayor sea la calidad del trabajador extranjero, tanto más será indicio de que su inteligencia está por encima de la de los oriúndos. En resumidas cuentas: todo extranjero que no venga a mendigar, es siempre útil al país, pues ó ha de traer a él fondos para consumirlos, ó para hacerlos productivos, ó ha de ejercer un ramode industria, y en todos los casos resulta un beneficio al país. Nuestro personaje cree también que, de los extranjeros inmigrados, hay mucho que aprender y beneficiarse. Y cita como ejemplo el de Inglaterra, que al acoger 
a los refugiados flamencos en tiempos de Isabel I, aprovechó sus conocimientos y puso así las bases de su prosperidad (88).

En resumidas cuentas, los gobiernos que se oponen a la buena acojida de los extranjeros, y que no conocen estas y otras muchas ventajas que su admisión proporciona a un país, están seguramente á medio civilizar. Cuanto más fuesen en número los extranjeros que encontrasen trabajo en el pais en que se fijan, más productivo harían su suelo y mayor sería el vigor que diesen á la industria, porque en ella sola tienen afianzada su subsistencia (89). Tampoco se ha de temer la repatriación de los capitales. Durante el tiempo de estancia de los extranjeros en el país de acogida, éste ha evitado tener que comprar fuera los productos que esos producían con un menor costo. Ello, de por sí, compensaría las eventuales pérdidas de la fuga de divisas. Y, en todo caso, ésta se puede evitar si los Estados proveen para que los extranjeros gocen de leyes justas (sic) que les desanimen de partir (90).

Es tiempo de recapitular. A lo largo de este recorrido, un tanto apretado, por la Historia Moderna de España hemos podido apreciar la persistencia de una queja: España y sus Indias se hallan a merced de los productos extranjeros, lo que equivale a decir, de las industrias de otros países. Incluso cuando parecen correr otros tiempos a nivel de las ideologías -léase el siglo XVIII- permanece la constatación, aun cuando el punto de vista que se tiene sea ya más positivo. A la hora de analizar las causas de esta dependencia, los tratadistas del XVI y XVII insisten en considerar al extranjero, en especial al comerciante, como culpable de este estado de cosas. A veces, se llega a un alto nivel de agresividad dialéctica para con él. En el fondo es la confesión de una importencia: las Indias, como España, necesitan de las manufacturas extranjeras $y$, por tanto, de los abastecedores de éstas. La actitud deja de ser pensamiento para convertirse en realidad en la ofensiva lanzada por el Consulado del Comercio de Indias contra los jenízaros y los propios extranjeros, al margen, incluso, del Consejo de Indias, quien posee al respecto una posición más contemporizadora.

Las medidas que se proponen son, según hemos visto, aunque variadas en el contenido, de corte bullonista (identificación de la riqueza de un país con la posesión de moneda) y mercantilista (o proteccionista), según suele ser propio de esta época (91). Es a través de limitaciones a la presencia y acción de olos extranjeros, cuando no de la simple y llana suplantación de los mismos, desde donde se quiere atajar el problema, sin ver claramente que son las deficiencias hispanas en el campo social y económico las que han arrastrado al país a la denunciada situación de dependencia. En todo ello existe un acuerdo generalizado, en Luis de Ortiz como en Abreu, o los arbitristas del siglo XVII.

Las cosas empiezan a cambiar en el Setecientos, aunque no de una forma inmediata. Los presupuestos liberales que llegan con la centuria y ese mayor pragmatismo que parece asistir a los reformistas de la Ilustración permiten un acercamiento al problema, en medio de no pocas tensiones, al verlo con ojos 
nuevos. Para salir de la dependencia, tal es su propuesta; no hay que acabar con el extranjero, sino aprovecharse de su presencia entre nosotros y liberalizar el comercio a fin de que se anime también a competir el negociante español, con independencia del lugar donde se encuentre. Abrir, en definitiva, el mercado indiano a las iniciativas particulares vengan del lado que vengan. Esto, que en Uztáriz es aún una utopía, se convierte en moneda corriente en los liberales, a los que Campomanes y antes (aunque más tímidamente) Ward han abierto las puertas. No será fácil el cambio de rumbo, si bien no pocas energías están en el país esperando poder dar el salto. La legislación borbónica, especialmente la carolina, lo preparan con las medidas de libre comercio de 1765 y 1778 . Estas, sin romper la idea de monopolio (no se abre el comercio indiano a los países extranjeros ni a todos los puertos hispano-americanos), recogen, sin embargo, los nuevos puntos de vista. En ese sentido, constituyen una respuesta a las propuestas teóricas y a los tiempos que corren. La emancipación colonial del primer cuarto del XIX, muy cerca de la época en que escribe Estrada, amenaza con no dejar al español tiempo para recoger los frutos; pero ésa es ya otra história.

\section{NOTAS.}

(1) Del impacto del Nuevo Mundo en España y Europa existe una excelente monografía, ya antigua, del profesor J.H. Elliott: El Viejo Mundo y el Nuevo (1492-1650), Madrid, Alianza, 1972.

(2) Vid. al respecto Jean-Pierre Sánchez, «L' Europe du Ponant et la découverte du Nouveau Monde: le rôle de l' imaginaire», en Dans le sillage de Colomb. L' Europe du Ponant et la découvert du Nouveau Monde (1450-1650), Rennes, P.U.R., 1995, pp. 249-264.

(3) La idea la expresó Pierre Chaunu en Conquète et exploitation des nouveaux mondes, París, P.U.F., 1969. Una síntesis de la misma en P. Chaunu, «De lo plural a lo singular», en P. León (dir.), Historia económica y social del mundo. La apertura del mundo siglos XIV-XVI, Madrid, 1980, vol. I, p. 15.

(4) Cambio que también experimentaron los portugueses durante sus periplos de los siglos XV-XVI. Vid. J.S. Da Silva Dias, Os descubrimentos e a problemática cultural do século XVI, Lisboa, Presença, 1982, espec. cap. VI. También Felipe Fernández-Arnesto, Antes de Colón. Exploración y colonización desde el Mediterráneo hacia el Atlántico, 1229-1492, Madrid, Cátedra, 1993, pp. 250 y sigs.

(5) Tomás de Mercado, Suma de tratos y contratos, ed. de Restituto Sierra, Madrid, Editora Nacional, 1975 ( $1^{\text {a }}$ ed. en 1569), pp. 253-261.

(6) La obra de Silvio Zabala, Filosofía de la conquista (México, F.C.E., 1984), sigue siendo, a pesar del tiempo transcurrido, un resumen claro de la posición de 
los tratadistas ante los problemas éticos planteados por la conquista de América y el sometimiento de los indios.

(7) Vid. sobre el tema P. Iradiel Murugarren, Evolución de la industria textil castellana en los siglos XIII-XVI. Factores de desarrollo, organización y costes de la producción manufacturera en Cuenca, Salamanca, 1974; A. García Sanz, Desarrollo y crisis del Antiguo Régimen en Castilla la Vieja. Economía y sociedad en tierras de Segovia 1500-1814, Madrid, Akal, 1977; J. Ignacio Fortea, Córdoba en el siglo XVI: las bases demográficas y económicas de una expansión urbana, Córdoba, Caja de Ahorros, 1981; Garzón Pareja, La industria sedera en España. El arte de la seda en Granada, Granada, 1972.

(8) Vid. al respecto M. Basas Fernández, El Consulado de Burgos en el siglo XVI, Madrid, 1963; T. Guirard, Historia del Consulado y Casa de Contratación de Bilbao, Bilbao, 1917; A. Marcos Martín, Auge y declive de un núcleo mercantil y financiero de Castilla la Vieja: Evolución demográfica de Medina del Campo durante los siglos XVI y XVII, Valladolid, 1978; F. Morales Padrón, La ciudad del Quinientos, vol. III de la Historia de Sevilla, Sevilla, Universidad de Sevilla, 1977, y A. Domínguez Ortiz, Orto y ocaso de Sevilla, Sevilla, Universidad de Sevilla, 1974.

(9) Un magnífico resumen comparativo entre estas zonas industriales de Europa en C.M. Cipolla, Historia económica de la Europa preindustrial, Madrid, Revista de Occidente, 1976, cap. VI.

(10) Un planteamiento general del tema en A.W. Lovett (La España de los primeros Habsburgos (1517-1598), Barcelona, Labor, 1989, pp. 243-246) y John Lynch (Los Austrias (1516-1598), Barcelona, Crítica, 1993, vol. X de la Historia de España dirigida por J. Lynch, pp. 146-147).

(11) El Memorial al Rey para que no salgan dineros de estos reinos de España del contador Luis Ortiz data de 1558. El manuscrito de este texto se encuentra en la Biblioteca Nacional ( ${ }^{\circ}$ 6487). Existe una edición de M. Fernández Alvarez en Anales de Economía (XVII, nº 63, 1957, pp. 101 a 200) y otra del Instituto de España, publicada en Madrid (1970) con introducción de José Larraz.

(12) Fray Pedro de Abreu, Historia del saqueo de Cádiz por los ingleses en 1596, ed. crítica, notas e introducción de Manuel Bustos Rodríguez, Cádiz, Servicio de Publicaciones de la Universidad, 1996, pp. 164 y 168.

(13) Sobre este autor, el estudio introductorio de J. Vilar Berrogain ( Conciencia nacional y conciencia económica. Datos sobre la vida y la obra del doctor Sancho de Moncada») a la obra de Sancho de Moncada, Restauración política de España, Madrid, Instituto de Estudios Fiscales, 1974. Los nueve discursos que componen la obra datan de 1619.

(14) Ibídem, p. 168. 
(15) Ibídem, pp. 148-150.

(16) Ibídem, p. 162.

(17) Ibídem, p. 103.

(18) Ibídem.

(19) lbídem, p. 163.

(20) Ibídem, p. 162.

(21) Ibídem, pp. 142 y 143.

(22) Ibídem, p. 111.

(23) Tbídem.

(24) Ibídem, p. 168.

(25) La edición que manejamos es la de Moneda y Crédito, editada y prologada por Gonzalo Anes (Madrid, 1971), bajo el título Memoriales y Discursos de Francisco Martínez de Mata. Allí hay una brevísima biografía del autor.

(26) Sobre el contexto que sirve de marco a la obra vid. R.A. Stradling, Felipe IV y el gobierno de España, 1621-1665, Madrid, Cátedra, 1989.

(27) G. Anes (ed. y nota preliminar), Memoriales y discursos, Discurso I, p. 111.

(28) Ibídem, Discurso I, p. 110.

(29) Ibídem, Discurso I, p. 101.

(30) Ibídem, Discurso I, pp. 99-100.

(31) Ibídem, vid. Discurso IV; también Discurso VI, pp. 154-155.

(32) Ibídem, pp. 192-194.

(33) Ibídem, vid. Discurso V; también nota preliminar, pp. 69-72.

(34) Ibídem, Discurso II, p. 119.

(35) Ibídem, Discurso VI, pp. 144 passim.

(36) Ibídem, Discurso VII, pp. passim. 
(37) Ibídem, p. 187.

(38) Al igual que los anteriores autores, la figura de Gerónimo de Uztáriz no posee una biografía satisfactoria, a pesar de su fama, no sólo en España (su obra llegó a tener dos ediciones, la primera en 1724 y la segunda en 1742), sino en la Europa de su tiempo (recuérdese la cita que de él hace Adam Smith en su Wealth of Nations). Tampoco existe una edición asequible de su Theórica y práctica de Comercio y Marina. Utilizamos la que en su día publicara el Fondo de Cultura Económica (Madrid, 1968), con introducción de Gabriel Franco. Las relaciones de Uztáriz con sus antecesores en Reyes Fernández Surán, «Gerónimo de Uztáriz. Las fuentes de su pensamiento económico», Información Comercial Española, Revista de Economía, n 512 (1976), pp. 75 a 100.

(39) Ibídem, cap. IV.

(40) Sobre el contexto general vid. Geoffrey J. Walker; Política española y comercio colonial (1700-1789), Barcelona, 1979. Más concretamente, Margarita García-Mauriño Mundi («Los jenízaros y el comercio indiano (17001750)», Revista de Temas Americanistas, $\mathrm{n}^{\circ}$ 6, Sevilla, 1986, pp. 21 a 28; «La precariedad legal de los jenízaros en el Consulado de Cádiz», Ibídem, nº 8, 1990, pp. 13 a 15) y M. C. García Bernal, «Los españoles, hijos de extranjeros en el comercio indiano», en La burguesía mercantil gaditana (1650-1868), Cádiz, I.EE.G., 1976, pp. 173-182.

(41) Sancho de Moncada, op. cit., pp. 150 a 152.

(42) Ibídem, Discurso IV, p. 164.

(43) Ibídem, Discurso IV, p. 165. En el Discurso II, p. 128, Moncada propone que, caso de no impedir la entrada de las mercancías extranjeras, se actúe sobre ellas de forma indirecta, cargándolas tan grandes alcabalas que no se gasten de caras.

(44) Ibídem, Discurso IV, pp. 165-166.

(45) Ibídem, Discurso IV, pp. 172-173.

(46) Ibídem, Discurso I, p. 109. En España -expresa- ya no hay oficiales, porque no trabajan, porque no gastan lo que hacen (p. 108).

(47) Ibídem, Discurso I, pp. 106-107, también Discurso I, p. 118.

(48) Ibídem, Discurso I, pp. 118-119.

(49) Ibídem, Discurso I, pp. 119-120. 
(50) Ibídem, Discurso II, p. 127.

(51) Gonzalo Anes (ed.), Memoriales y Discursos, Discurso VI, pp. 152-153.

(52) Ibídem, Memorial en razón de la despoblación y pobreza de España y su remedio, pp. 308 y sigs.

(53) Ibídem, Discurso VIII, p. 254.

(54) Ibídem, Memorial en razón, pp. 304-306.

(55) J. Muñoz Perez, «Ideas sobre el comercio en el siglo XVIII» (Anuario de Estudios Americanos, $\mathrm{n}^{\circ} 100$ (Sevilla, 1962), pp. 47 a 66) y «El comercio de Indias bajo los Austrias y la crítica del Proyectismo del siglo XVII» (Ibídem, vol. XIII (Sevilla, 1956), pp. 85-103).

(56) «Elogio de Carlos III leído a la Real Sociedad de Madrid por el socio D. Gaspar Melchor de Jovellanos en la Junta plena del sábado 8 de noviembre de 1788, con asistencia de las Señoras Asociadas. Impreso de acuerdo de la misma Sociedad», Madrid, Impre. Viuda de Ibarra, 1789, pp. 18 a 21.

(57) Vid. ut supra pp. 40.

(58) Antonio García Baquero, Cádiz y el Atlántico (1717-1778), Sevilla, E.E.H.A., 1976, vol. I, pp. 95-96.

(59) Margarita García-Mauriño Mundi, La pugna entre el Consulado de Cádiz y los jenizaros por las exportaciones a Indias (1720-1765), Tesis Doctoral, Universidad de Sevilla, 1992, p. 42.

(60) Nos referimos a la Restauración de la abundancia de España, cuya primera edición data de 1631 (hay reedición del Instituto de Estudios Fiscales de 1975 a cargo de J. Paul Le Flem).

(61) M. García-Mauriño, op. cit., p. 43.

(62) Ibídem, p. 48.

(63) Ibídem.

(64) Ibídem, p. 50.

(65) Ibídem, pp. 65 y sigs.

(66) J. Luis Castellano, estudio preliminar a la obra de Bernardo Ward, Proyecto económico, Madrid, Instituto de Estudios Fiscales, 1982, pp. XIX y sigs. 
(67) Ibídem, pp. IX y sigs.

(68) Ibídem, parte II, cap. VII, p. 312.

(69) Ibídem, pp. 313 a 315.

(70) Tbídem, p. 315.

(71) Ibídem.

(72) Tbídem, p. 316.

(73) Tbídem, p. 317.

(74) Ibídem, pp. 318-319.

(75) Ibídem, p. 319.

(76) Ibídem, p. 322.

(77) Ibídem, pp. 323-324.

(78) Nos referimos al Apéndice IX de la obra citada ut supra pp. 25. En origen fueron publicadas en el tomo IV del Apéndice a la Educación Popular de los Artesanos atribuida a Campomanes.

(79) Sobre el pensamiento económico del personaje vid. Manuel Bustos Rodríguez, El pensamiento socio-económico de Campomanes, Oviedo, I.E.A., 1982.

(80) G. Anes (ed. y nota preliminar), op. cit., p. 527, nota 103.

(81) Ibídem, p. 526, nota 103.

(82) Tbídem, p. 542, nota 176.

(83) Ibídem, p. 543, nota 176.

(84) Ibídem, p. 533, nota 136.

(85) Ibídem, p. 546, nota 188.

(86) Alvaro Flores Estrada, Curso de Economía Política por D...., Londres, D.M. Calero, 1828, vol. I, p. 243.

(87) Ibídem. 
(88) Ibídem, pp. 243-244.

(89) Ibídem, pp. 243-244.

(90) Ibídem, pp. 245-246.

(91) Pierre Vilar, «Los primitivos españoles del pensamiento económico: cuantitativismo y bullonismo», en Crecimiento y desarrollo, Barcelona, 1974. 